\title{
Epidemiology of Asthma in 94 Children with Atopic Dermatitis
}

\author{
Arnaldo Cantani* \\ Allergy and Immunology Division, Department of Pediatrics, University of Rome La Sapienza, Italy
}

Received: February 19, 2015; Accepted: April 23, 2015; Published: April 30, 2015

*Corresponding author: Arnaldo Cantani, Allergy and Immunology Division, Department of Pediatrics, University of Rome La Sapienza, Via Baglivi 7, I 00161 Roma, Italy, Fax: +0039-0644230256; E-mail: acantani@pelagus.it

\begin{abstract}
In this paper we present 94 children affected with Atopic Dermatitis (AD), aggravated by respiratory allergy, asthma and/ or Allergic Rhinitis (AR). AD is a common disorder, frequently complicated by asthma-like symptoms, we debate either disorder and concluded that both AR and asthma can afflict most babies with $\mathrm{AD}$, especially when both parents smoke. We confirm our previous statistics, according to which little children not fed breast milk may react to smallest doses of allergens.
\end{abstract}

Keywords: Asthma; Atopic dermatitis; Allergic rhinitis; Cow milk

\section{Introduction}

Atopic Dermatitis (AD) has a clinical pattern which often manifests itself in association with a personal and/or family history of atopic respiratory disorders such as asthma or allergic rhinitis. AD is characterized by a clinical pattern dominated by eczematic skin lesion and itching, which provokes an unremitting scratching, aggravating the lesions and is frequently associated with asthma and/or AR [1-5].

\section{Materials and Methods}

Among 855 children extractedfrom the card-file of AD by chance (with the aleatory numbers) we selected 94 babies of either sex aged 3-6 years affected with both AD and asthma and/or AR, all children less two were fed maternal milk for 1- 6 months (median 4,5), after which they were weaned Cow's Milk (CM) diluted with water. The first CM weaning precipitated the symptoms, such as vomiting and diarrhea and the babies were mostly fed soy milk. Appropriate emergency equipment and medications were available on site. All possible drugs were stopped at least 2 weeks before the application of the SPTs. Ninety three healthy babies of the same age and sex with the permission of their parents were the controls. SPTs were done at baseline by the prick method on the volar surface of the forearm by myself with the co-operation of a qualified nurse. The skin was marked with a ballpoint pen for the allergens to be tested. The babies were then tested with: histamine hydrochloride $(1 \mathrm{mg} / \mathrm{ml})$ as a positive control and isotonic saline as a negative control. We continued with a battery of food allergens, including whole CM protein, beta-lactoglobulin, casein, lactalbumin and a battery of inhalant allergens, including house dust mite pollen, dust, dust mite, mold, animal dander (Lofarma). The diagnostic extract of each individual allergen was placed on the volar surface of the forearm as drops through which the skin was superficially pricked with a straight pin for one second. A new pin was used for each SPT and then discarded, and the drop of the extract was then wiped off about one minute after the prick.

\section{SPT reading}

SPTs were read 20 minutes after the test was finished and considered positive as follows:

+ when the wheal was the half of the histamine wheal;

++ when the wheal was equal to the histamine wheal;

+++ when the wheal was two-fold the histamine wheal;

++++ when the wheal was more than two-fold the histamine wheal.

We took for positive only children with a +++ or ++++ reaction, that is a wheal $=3 \mathrm{~mm}$ with an area $=7 \mathrm{~mm}^{2}$ (cut-off). So we considered as positive only the children with a mean wheal diameter of $3 \mathrm{~mm}$ or larger than the negative (saline) control. A positive (histamine) control was performed to ensure the absence of any antihistamine drug interference.

\section{Statistical analysis}

The statistical analysis was performed using the $\mathrm{X} 2$ test. Results with a $p<0.05$ were considered as statistically significant. At the $\mathrm{CM}$ reintroduction, for diagnostic purposes, all babies presented again with diarrhea, one with a short state of shock promptly regressed after immediate parenteral treatment. The 94 healthy controls, similar for sex and age had no clinical reactions by eating whatever food.

\section{Results}

All 94 babies suffered from either respiratory or food allergy. Among them 23 (24.9\%) were affected by both AD and respiratory allergy. Of these 23, 13 children, 7 males and 6 females, aged between 2 and 6 years, median 3, showed a positive Food Provocation Test (FPT) and in the remaining 10 
negative, 6 males and 4 females aged between 2 and 9 years, median 5.5 the test was negative. We stress that some children reacted to very small doses of allergens: 14 asthmatic children fed foods reacted with wheezing. Therefore, I recommend that in FPTs, medical doctors with resuscitation equipment are present on the scene since the first moment. It is of note that the statistical analysis had a highly significant difference with SPTs ( $p=0.013)$. However, 80/94 children (85.1\%) had SPTs done and only 46 the RAST.

\section{Discussion}

An important result is suggested by Nwaru et al. [6]: Allergic sensitization to any food allergen was associated with late introduction of potatoes ( 4 months), oats (5.5 months), rye (7 months), meat (5.5 months), fish ( 8.2 months), and eggs (10.5 months) who studied 994 children. The median duration of exclusive breastfeeding in the whole study population was 1.8 months (range: $0.0-10.0$ months). In this study breastfeeding was continued for 1- 6 months however we have calculated the median 4.5), which gives a high duration of breastfeeding. We suggest that a longer duration of breast feeding, as in the present study may have protected the children by Nwaru et al. [6] $\mathrm{AD}$ complicated by asthma and or AR is a severe disease, which poses in the first place the house dust controls. The children in this study were protected from cigarette smoke since beginning.
The study by Nwaru et al. [6] says that mothers failed to smoke only during pregnancy and the children must be prevented from wheezing, a severe disease $[7,8]$.

\section{References}

1. Cantani A. The first world diagnosis of allergy. J Allergy Ther. 2013; 4: 136-40. doi: 10.4172/2155-6121.1000136.

2. Businco L, Benincori N, Cantani A. Clinical and immunological aspects of atopic dermatitis: a review and update. Advances in Pediatric Allergy. Excerpta Medica. 1982.

3. Rajka G. International Symposium on Atopic Dermatitis. Munich. 2014.

4. Hanifin JA. Rajka G. Diagnostic features of atopic dermatitis. Acta Derm Venereol. 1980; Suppl 92: 44-47.

5. Cantani A. Pathogenesis of atopic dermatitis (AD) and the role of allergic factors. Eur Rev Med Pharmacol Sci 2001; 5(3): 95-117.

6. Nwaru BI, Erkkola M, Ahonen S, Kaila M, Haapala AM, KronbergKippilä C, et al. Age at the introduction of solid foods during the first year and allergic sensitization at age 5 years. Pediatrics. 2010; 125(1): 50-9. doi: 10.1542/peds.2009-0813.

7. Cantani A. Pediatric asthma before treated should be prevented. Eur Rev Med Pharmacol Sci. 1999; 3(5): 237-8.

8. Piippo-Savolainen E, Remes S, Korppi M. Does early exposure or sensitization to inhalant allergens predict asthma in wheezing infants? A 20-year follow-up. Allergy Asthma Proc. 2007; 28(4): 454-61. 